Article

\title{
Assessing the Impact of COVID-19 Pandemic on the Stock and Commodity Markets Performance and Sustainability: A Comparative Analysis of South Asian Countries
}

\author{
Farhan Ahmed ${ }^{1, *(\mathbb{D}}$, Aamir Aijaz Syed ${ }^{2}{ }^{(}$, Muhammad Abdul Kamal ${ }^{3}{ }^{(D}$, Maria de las Nieves López-García ${ }^{4}$, \\ Jose Pedro Ramos-Requena ${ }^{4}$ and Swati Gupta ${ }^{5}$ \\ 1 Department of Economics and Management Sciences, NED University of Engineering \& Technology, \\ Karachi City 75270, Pakistan \\ 2 Institute of Management, Commerce and Economics, Shri Ramswaroop Memorial University, \\ Lucknow 226018, India; aamirank@gmail.com \\ 3 Department of Economics, Abdul Wali Khan University, Mardan 23200, Pakistan; kamal@awkum.edu.pk \\ 4 Department of Economics and Business, University of Almeria, 04003 Almeria, Spain; \\ mlg252@ual.es (M.d.l.N.L.-G.); juramos@ual.es (J.P.R.-R.) \\ 5 Motilal Nehru National Institute of Technology, Uttar Pradesh 211004, India; Swatigupta130192@gmail.com \\ * Correspondence: fahmed.ned@gmail.com
}

Citation: Ahmed, F.; Syed, A.A.; Kamal, M.A.; de las Nieves López-García, M.; Ramos-Requena, J.P.; Gupta, S. Assessing the Impact of COVID-19 Pandemic on the Stock and Commodity Markets Performance and Sustainability: A Comparative Analysis of South Asian Countries. Sustainability 2021, 13, 5669. https://doi.org/10.3390/su13105669

Academic Editors: Mário José Baptista Franco, Margarida Maria Mendes Rodrigues and Bruce Morley

Received: 19 March 2021

Accepted: 13 May 2021

Published: 18 May 2021

Publisher's Note: MDPI stays neutral with regard to jurisdictional claims in published maps and institutional affiliations.

Copyright: (c) 2021 by the authors. Licensee MDPI, Basel, Switzerland. This article is an open access article distributed under the terms and conditions of the Creative Commons Attribution (CC BY) license (https:// creativecommons.org/licenses/by/ $4.0 /)$.

\begin{abstract}
COVID-19 is certainly the first sustainability crisis of the 21st century. The paper examines the impact of COVID-19 on the Indian stock and commodity markets during the different phases of lockdown. In addition, the effect of COVID-19 on the Indian stock and commodity markets during the first and second waves of the COVID-19 spread was compared. A comparative analysis of the stock market performances and sustainability of selected South Asian countries is also included in the study, which covers the lockdown period as well as the time frame of the first and second waves of COVID-19 spread. To examine the above relationship, the conventional Welch test, heteroskedastic independent $t$-test, and the GMM multivariate analysis is employed, on the stock return, gold prices, and oil prices. The findings conclude that during the different phases of lockdown in India, COVID19 has a negative and significant impact on oil prices and stock market performance. However, in terms of gold prices, the effect is positive and significant. The results of the first wave of COVID-19 infection also corroborate with the above findings. However, the results are contradictory during the second wave of coronavirus infection. Furthermore, the study also substantiates that COVID-19 has significantly affected the stock market performances of selected South Asian countries. However, the impact on the stock market performances was only for a short period and it diminished in the second wave of COVID-19 spread in all the selected South Asian countries. The findings contribute to the research on the stock and commodity market impact of a pandemic by providing empirical evidence that COVID-19 has spill-over effects on stock markets and commodity market performances. This result also helps investors in assessing the trends of the stock and commodity markets during the pandemic outbreak.
\end{abstract}

Keywords: COVID-19; stock market; commodity market; pandemic

\section{Introduction}

The stock and commodities markets are often akin to volatilities, which are subjected either to some rare economic conditions or natural phenomena [1]. A pandemic is, unfortunately, such a natural phenomenon that creates absurd shocks in the financial and economic conditions. The novel coronavirus is also a rare example of such a kind of pandemic, which started spreading at the end of December 2020. In China, the first COVID-19 case was reported on 3 January 2020, and on 30 January 2020, the World Health Organization (WHO) issued its global alert [2]. As the deadly disease started spreading around the world, on 30 March 2020, the World Health Organization declared it a pandemic [3]. Initially, the World 
Health Organization suggested social distancing and wearing a face mask as measures to curb the spread of COVID-19; later on, due to a sudden rise in the number of cases in India and the world, most of the countries started enforcing complete lockdown. The prolonged and stringent lockdown affected both the social and economic conditions of individuals as well as the economic sustainability of countries. Previous studies suggested that unexpected events like terrorist attacks and SARS pandemics have severe impacts on the economic and financial conditions of individuals [4]. Such events create a sense of fear and panic in the mind of individuals, apart from distorting the demand for goods, money supply, and labor movements [5]. The United States stock market witnessed a circuit breaker four times in ten days in March due to the uncertainties caused by the drastic spread of coronavirus, and along with the U.S. stock market, Asian and European stock markets also noticed a sudden plunge [6]. Due to the COVID-19 outbreak, similar to the stock market performance, the commodity markets also showed abrupt movement. The prices of oil recorded a negative price in April for the first time in history due to low demand from the world market, and similarly, gold prices also showed abrupt movements, from the lowest prices in March to the highest prices in May 2020 [7].

The previous studies suggest that investors consider accounting information as the benchmark for making their investment decisions in capital and commodity markets. The release of new accounting information helps in analyzing the market reaction. However, sometimes due to unforeseen situations like pandemics and natural calamities, accounting information becomes redundant in gauging the market reactions [8]. This uncertainty and volatility in the stock and commodities market motivated us to examine the impact of COVID-19 on the Indian commodity and stock markets along with comparing the volatility of the stock markets of selected South Asian countries. In India, the first COVID-19 case was found in Kerala in January 2020, but safety measures were introduced from March 2020 onwards after the World Health Organization declared it as a global pandemic. By the time of completing this study (16 April 2021), India has confirmed COVID-19 cases of $14,526,609$, where out of these active cases, there are 1,679,121, and total deaths are 175,673, as per the data released by the Ministry of Health and Family Welfare, Government of India. Currently, India is witnessing the second wave of coronavirus infection, which is more severe due to the high death rate compared to the first one. The first wave of the COVID-19 spread in India was subdued during the first week of November 2020. Since March 2020, the Indian government has implemented lockdowns in five stages, under which the first three were stringent and complete lockdowns, whereas the remaining two lockdowns were more unlocking in nature. These lockdowns have significantly affected the economic fundamentals of the Indian economy, which is one of the fastest emerging economies of South Asia. Such uncertainty, lockdowns, and the emergence of the second COVID-19 wave have encouraged us to examine the direct impact of COVID-19 cases on the Indian commodity and stock markets.

South Asia is one of the most populated regions of the world, with one-fourth of the world population living on less than 3.4 percent of its total surface area [9]. In South Asia, the prominent countries in terms of the number of novel coronavirus cases are India, Pakistan, and Bangladesh, and since the World Health Organization declared COVID-19 as a global pandemic, there is a sudden surge in the number of cases in these countries. Due to the large population and weak healthcare infrastructure, researchers are apprehensive about the impact of COVID-19 on the markets of South Asian countries. As the selected countries (India, Pakistan, and Bangladesh) are among the emerging markets of South Asia in terms of consumption and domestic demand, this further motivated us to analyze how this pandemic will impact the stock markets of the aforementioned South Asian countries.

To achieve the stated objectives, we have conducted the study into two parts. The first part focuses on investigating the impact of COVID- 19 on the Indian stock and commodity market by taking two timelines. The first timeline focus on different phases of lockdown imposed by the government of India and the second timeline evaluates the above relationship by comparing the impact during the first wave and second wave of coronavirus 
infection. The second part of the study focuses on analyzing the impact of COVID-19 spread on the stock market performance of India, Pakistan, and Bangladesh. The second part of the study is also segmented into two timelines: the first timeline studies the impact during the lockdown period and the second timeline covers the period of the first wave and second wave of COVID-19 spread. By studying mean variation through the Games-Howell test, the findings suggested that coronavirus-induced lockdown phases (1 and 2) have a significant and negative impact on the Indian stock market and oil prices, whereas the effect is positive in terms of gold prices. The findings also suggest that such impact was subdued in the later stages of lockdown, as people become more aware of the severity of the virus. The results of the first wave of COVID-19 spread also support the above findings that stock markets and oil prices have a negative relationship with coronavirus infection whereas gold has a positive relationship. However, the results are contradictory during the second wave, which concludes that oil and stock have a positive relationship whereas gold prices have a negative relationship with COVID-19 spread. Furthermore, the results of the comparative analysis of the stock market performance of South Asian countries conclude that during the pre- and post-lockdown phases, COVID-19 has a significant and negative effect on the stock market performance of the selected South Asian countries. The stock market shares have a negative relationship with novel coronavirus during the first wave of infection, whereas, during the second wave of infection, this relationship becomes positive.

The novel coronavirus, which poses serious threats to economic and financial sustainability, has emerged as a hot topic for researchers to investigate. However, few studies have examined such direction, i.e., examining the impact of lockdown and evaluating the comparative analysis during the first wave and second wave of COVID-19 spread in context to the South Asian region, thus providing a suitable literature void. The other reasons through which this study substantially contributes to the previous literature are as follows: first, this study documents the current effects of COVID-19 on the Indian stock and commodity markets by performing a comprehensive comparative analysis with stock performance of selected South Asian countries. Second, this study considers the two most essential commodities that are gold and oil prices, together with the stock market index, and to the best of the authors' knowledge, these three variables have never been used in the empirical analysis. Third, this study measures the impact of different phases of lockdown on the performance and sustainability of the Indian stock market and commodity markets. Fourth, this study assesses the impact of the first and second waves of coronavirus infection on the Indian stock and commodity markets, as well as the South Asian market, which has yet to be investigated, thus contributing to the existing literature. Last, this study also uses both mean-variance analysis and multivariate analysis to make the findings more robust and conclusive.

The paper further proceeds as follows: the second part of the study focuses on research methodology and theoretical background. The third section covers the data analysis and methodology section, and the last section covers the concluding remarks.

\section{An Overview of Empirical Studies and Theoretical Background}

This section of the study focuses on the previous literature related to the impact of the pandemic and unexpected events on the stock and commodity markets, along with discussing the theoretical framework.

There are limited studies that focus on studying the impact of COVID-19 and unexpected events on the stock and commodity markets based on lockdown stages and the first and second wave of infections. Chen et al. [10] studied the effect of SARS on the performance of the hotel exchange in mainland China. His study concluded that the pandemic has a negative and significant impact on stock performances due to constant emotions of fear and panic in the mind of investors. The work of Burch et al. [11] reported similar findings that terrorism and unfortunate pandemics severely impact investors and create a sense of panic selling among them. Mirza et al. [12] conducted a study on COVID-19 and its impact on stock markets. He investigated the volatility of the European investment 
fund during the COVID-19 outbreak. The study concluded that as the outbreak progresses, investment funds exhibited stressed performance in all the prominent sectors except for social funds. Papadamou et al. [13] also conducted a similar work by exploring the trend of Google searches during COVID-19 and their impact on stock performances. The findings suggested that market volatility is directly affected by the corona conditions in 13 major developed stock markets around the world. These results also support and substantiate the work of Da et al. [14], which concluded that at times of stress and uncertainty, Google search affects stock market volatility. Liu et al. [15] studied the impact of COVID-19 on 27 leading stock markets, and findings suggested that the returns of all the leading stock markets are negatively affected by the outbreak of corona and the pessimistic view of investors. Other prominent studies that represented a similar relationship are Del and Paltrinieri [16], Chiang et al. [17], and Hasan et al. [18].

A pandemic is often associated with low demand and consumption. A study conducted by Siu and Wong [19] focusing on Hong Kong SARS pandemic and its economic impact concluded that in Hong Kong, the pandemic resulted in low domestic as well as international demand for goods and services. Similar results are also reported by DeLisle [20], who concluded that the 2003 SARS pandemic had resulted in a loss of around $\$ 3$ trillion in value of the gross domestic product. Chen [21] investigated the consumption pattern of 214 cities of China during the corona outbreak and reported that the consumption decrease is prevalent across cities, with the highest drop in the epicenter Wuhan (by 70\%), followed by the low online demand of goods and services. Albulescu [22] explored the oil demand and financial volatility in the United States during the corona outbreak using Auto-Regressive Distribution Lag and concluded that as the infection in the United States is rising, oil demand is showing a downward trend. Other studies that supported the above findings are Fornaro and Wolf [23] and Wren-Lewis [24].

The rationale of the above study rests on the postulate of investment decisions under the uncertainty theory given by JCT Mao [25], who proposed that at times of uncertainty, investors become apprehensive and resort to indiscriminate selling to avoid any future losses. Investment in financial products especially in stock markets needs a high degree of involvement since the process is affected by uncertainty and complexity of results. Traditional theories on investment decision-making are built on the belief in rationality and self-interest. In the context of financial market investment, the rationality of the decision involves behavioral economics, a field that suggests that the investor is unable to make rational decisions during the time of uncertainty.

The novel coronavirus has also created a sense of uncertainty among the people regarding their work status and financial conditions. Since the global onset of this virus, there has been a persistent lockdown, which hampered all sorts of economic activities. The people are uncertain about the efficacy of the vaccines and are also in a panic to see the sudden surge in the positive cases, especially in India, Pakistan, and Bangladesh. These uncertain situations lead to hasty investment and selling decisions, encouraging us to analyze the nexus between COVID-19 cases and their effects on the financial and commodity markets based on the postulate of uncertainty theory.

Along with the uncertainty theory, this paper also rests on the theoretical approach of demand theory, which states that price and demand are interlinked, and a change in one variable significantly affects the other variable. The spread of this virus has resulted in the closure of all sorts of industries like education, construction, travel and tourism, aviation, and others, which has resulted in slow demand for goods and services. This lower demand has resulted in stockpiling and losses to the industrialist and producers, further prompting us to investigate that how stages of lockdown and novel coronavirus first and second spread have impacted the prices of gold and oil prices based on the approach of demand theory. So, these theoretical backgrounds, and the limited availability of literature on the aftereffect of COVID-19 on the stock and commodity market of South Asian countries, provide a sufficient research gap. 
In a nutshell, a review of previous literature, and the market volatility, as shown in Figure 1, encourages us to see how COVID-19 spread and lockdown have impacted the demand for gold and oil prices in India, followed by financial volatility in terms of stock markets return in selected South Asian countries.
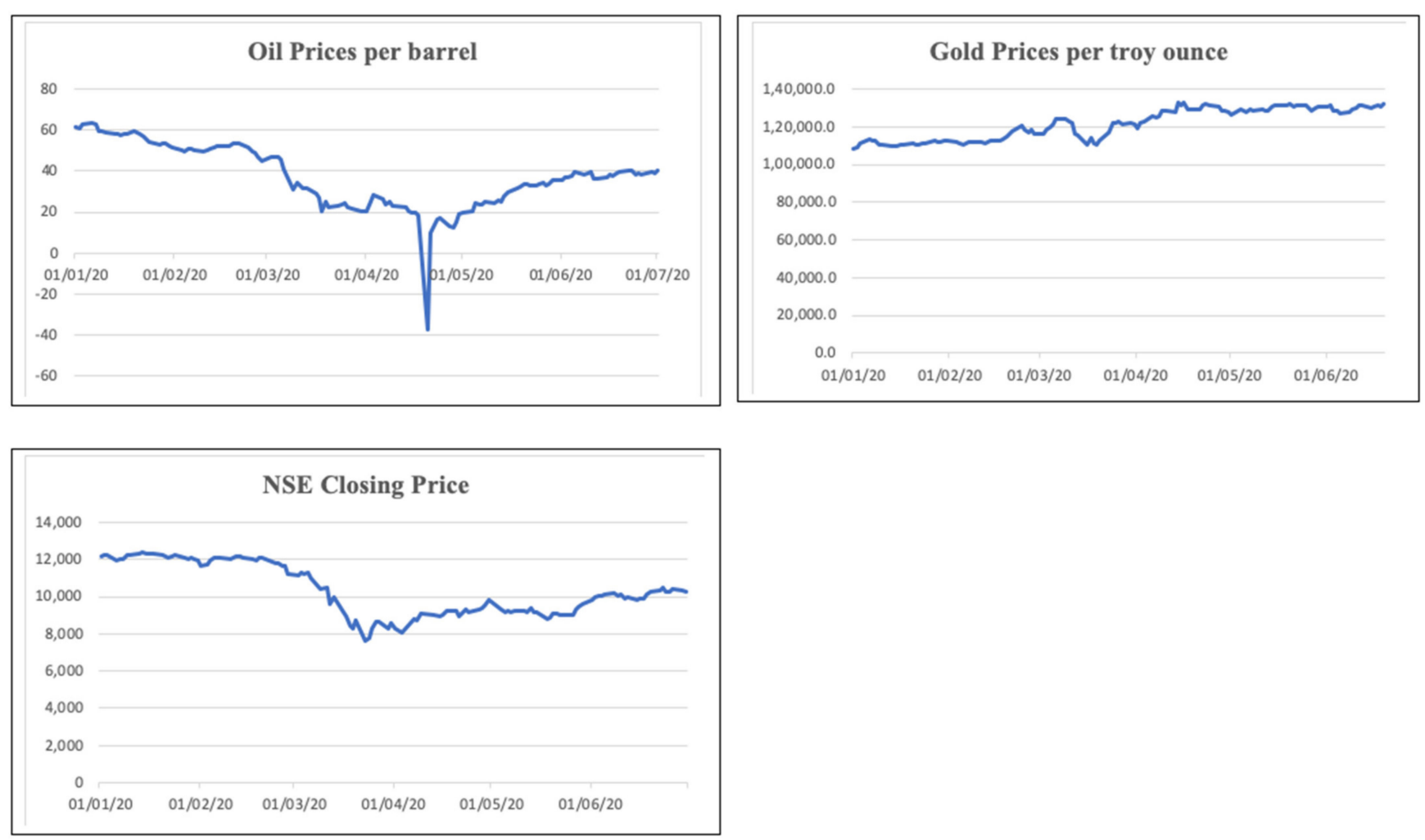

Figure 1. Daily price variation in gold, stock, and oil prices in different phases of lockdown.

\section{Material, Method, and Variable Description}

To examine the impact of COVID-19 on the Indian stock and commodity market, we have taken the daily closing price data of the National Stock Exchange index (NSE) and closing prices of gold and oil from the Multi Commodity Exchange (MCX) of India. We have considered only gold, oil, and stock index as they are more volatile compared to other variables. Further, the percentage of investment is also higher in these commodities as compared to others variables. Apart from that, to make a comparative analysis among the COVID-19 infection and stock market performances of South Asian countries, we have taken the daily closing price data of Pakistan Stock Exchange index and Dhaka Stock Exchange index and for measuring COVID infection, we have taken the daily COVID cases data from the European Centre for Disease Prevention and Control database. Other South Asian countries are not included in this study due to lack of data availability and also because the impact of COVID-19 is not so severe in other South Asian countries as compared to India, Pakistan, and Bangladesh.

This study is segregated into two parts: the first part investigates the stock and commodity markets' volatility of the Indian stock and commodity market. The first part is further categorized into two timelines: the first timeline studies the phases of lockdown as imposed by the government of India, and the second timeline focuses on the comparison between the first and second waves of COVID-19 infection. The second part of this study focuses on the stock market comparison among India, Pakistan, and Bangladesh by segregating the data into pre- and post-lockdown period. The post-lockdown period is considered until 31 July based on the uniformity of lockdown imposition in all three South Asian countries. Furthermore, the second part of the study also examines the stock market 
performance during the first and second waves of COVID-19 infection. Table 1a,b shows the timeline for both segments of the study. The following hypothesis is framed based on the time frame of the COVID-19 pandemic and segmentation of lockdown imposed.

Table 1. (a). Timeline for different phases of lockdown in India. (b). Timeline for comparative analysis between South Asian Country.

\begin{tabular}{|c|c|c|}
\hline \multicolumn{3}{|c|}{ (a) } \\
\hline \multicolumn{2}{|c|}{ Phases of Lockdown } & Dates \\
\hline \multicolumn{2}{|c|}{ No lockdown (No COVID) } & 1 January to 20 March 2020 \\
\hline \multicolumn{2}{|c|}{ 1st Lockdown (Phase 1) } & 23 March to 14 April 2020 \\
\hline \multicolumn{2}{|c|}{ 2nd Lockdown (Phase 2) } & 15 April to 30 April 2020 \\
\hline \multicolumn{2}{|c|}{ 3rd Lockdown (Phase 3) } & 1 May to 18 May 2020 \\
\hline \multicolumn{2}{|c|}{4 Lockdown (Phase 4) } & 19 May to 31 May 2020 \\
\hline \multicolumn{2}{|c|}{5 Unlock phase (Unlock) } & 1 June to 20 July 2020 \\
\hline \multicolumn{2}{|c|}{ First Wave of COVID infection } & 23 March 2020 to 30 November 2020 \\
\hline \multicolumn{2}{|c|}{ Second Wave of COVID infection } & 1 February 2021 to 16 April 2021 \\
\hline \multicolumn{3}{|c|}{ (b) } \\
\hline \multicolumn{2}{|r|}{ Pre-Lockdown } & Post-Lockdown \\
\hline India & 1 January to 20 March 2020 & 23 March to 31 July 2020 \\
\hline Pakistan & 1 January to 20 March 2020 & 23 March to 31 July 2020 \\
\hline Bangladesh & 1 January to 20 March 2020 & 23 March to 31 July 2020 \\
\hline & First Wave & Second Wave \\
\hline $\begin{array}{l}\text { India, Pakistan, } \\
\text { Bangladesh * }\end{array}$ & $\begin{array}{l}23 \text { March } 2020 \text { to } 30 \\
\text { November } 2020\end{array}$ & 1 February 2021 to 16 April 2021 \\
\hline
\end{tabular}

Hypothesis 1 (H1). Coronavirus has a significant negative impact on the performance of the stock and commodity market.

Hypothesis 2 (H2). The volatility of stock and commodity markets is higher in the first wave compared to the second wave of COVID-19 spread.

Table 1a represents the dates of different phases of lockdown as implemented by the government of India to curb the infection of novel coronavirus, together with the timeline of COVID-19 first and second waves. The timeline for the first and second waves is selected based on the rise and fall in the cases of novel coronavirus. In all the three countries, the maximum caseload was around the month of July-August and all the three countries witnessed a fall in peak load from the end of November onwards [26,27]; therefore, to ease the comparison, we have taken the first wave to have been until 30 November 2020. Similarly, from the start of February 2021, all three countries have again witnessed a steep rise in the number of COVID-19 cases; therefore, we have taken 1 February as the onset of the second wave in these three South Asian countries [27].

Table $1 \mathrm{~b}$ shows the pre- and post-lockdown timelines due to the COVID-19 infection scenario in India, Bangladesh, and Pakistan, along with the timelines of COVID-19 first and second waves. Pre- and post-lockdown timelines are decided based on the increase in infection in the selected countries, and as all three countries implemented lockdown at almost the same time [27]. Thus, to maintain uniformity, we have taken a standard timeline, from 1 January to 20 March 2020, as pre-lockdown scenarios, and from 23 March to 31 July 2020 as post-lockdown timeline. Even though the pandemic is still ongoing, we have set 31 July 2020 as the end of the post-lockdown period since all three selected countries experienced the highest caseload within the first three months and also uncertainty. Therefore, to measure the short-run impact and gauge the high level of investor irrationality, we have taken 31 July as the post-lockdown end date. Furthermore, 20 March is taken as 
the separation date, as during this time reportedly COVID-19 started spreading outside of China.

In the first part of the study, we used descriptive analysis, Welch test (substitute for one-way ANOVA in case of the violation of the assumption of homogeneity of variance), and the Games-Howell test (post hoc) to find out the deviation of stock returns and commodity market from their means, during the different phases of lockdown. Further, we have used heteroskedastic independent $t$-test to study how the above relationship changed in India during the first and second waves of COVID-19 spread. The heteroscedastic independent $t$-test has been used as the variances were not equal during the first and second waves of COVID-19 spread.

To achieve the objectives of the second part of the study, we have used a similar methodology on the dataset of selected South Asian countries. According to Chen and Siems [28], the t-statistics test is the appropriate estimation test to check the significance of the economic impact of an event on the capital market and commodity markets as measured by the deviation of index returns from their mean average. For hypothesis testing, these methods are also more comprehensive and robust [28]. However, to confirm and substantiate the results of the above analysis, we have also used the Generalized Method of Moment (GMM) technique as suggested by Arellano and Bond [29] and Arellano and Bover [30]. The traditional regression methods like ordinary least square, fixed, and random effect models sometimes show econometric errors due to their static natures. Thus, to avoid these biases, the GMM model is used as it considers instrumental variables [31]. Further, the GMM technique is more appropriate for the analysis of small sample size and unbalanced data. The model also provides robust results in the case of endogeneity, heteroskedasticity, and stationarity [32]. However, to apply the GMM estimation technique, it is required that none of the variables has to be I (2) order of integration. To check the order on integration, we have used the Augmented Dickey-Fuller test (ADF), the unit root test confirms that the data is of mixed order of integration, and none of the variables is of second-order integration, which is the pre-requisite for applying one lag GMM estimation. Equation (1) represents the model used for GMM estimation, and Appendix A shows the results of the Augmented Dickey-Fuller unit root test.

$$
S T_{i t}=\alpha+\gamma S T_{i, t-1}+\beta^{\prime} X_{i, t}+v_{i}+\varepsilon_{i, t}
$$

where, ST represents dependent variable (stock market returns), $\alpha$ denotes constant term, it denotes time-variant and cross-sectional, $X_{i, t}$ represents vector of independent variables (daily death rates, daily COVID-19 positive cases), $\beta^{\prime}$ is the coefficients vector, $v_{i}$ is the unobserved country-specific effects, and $\varepsilon_{i, t}$ is the error terms.

\section{Result and Discussion}

Initially, we investigated the Indian stock and commodity market volatility by exploring the descriptive statistics of the National Stock Exchange indices and gold and oil closing prices during the different phases of lockdown and also during the first wave and second wave of COVID-19 spread. Table 2 shows the result of the descriptive analysis.

Table 2. Descriptive Statistic.

\begin{tabular}{|c|c|c|c|c|c|c|c|c|c|}
\hline \multicolumn{4}{|c|}{$\begin{array}{c}\text { Gold (India) } \\
\text { (Rs. Troy Per Ounce) }\end{array}$} & \multicolumn{3}{|c|}{ Oil (India) (per Barrel) } & \multicolumn{3}{|c|}{ National Stock Exchange (India) } \\
\hline & $\mathbf{N}$ & Mean & Std. Dev & $\mathbf{N}$ & Mean & Std. Dev & $\mathbf{N}$ & Mean & Std. Dev \\
\hline $\mathrm{No}$ & 58 & $113,789.9$ & 3974.56 & 59 & 49.88 & 10.16 & 57 & $11,560.40$ & 1065.62 \\
\hline Phase 1 & 17 & $123,918.8$ & 3889.14 & 17 & 23.11 & 2.30 & 13 & 8453.38 & 446.06 \\
\hline Phase 2 & 13 & $129,947.4$ & 1789.41 & 13 & 12.03 & 15.26 & 12 & 9263.35 & 259.60 \\
\hline Phase 3 & 11 & $129,461.6$ & 1194.86 & 11 & 25.56 & 3.08 & 11 & 9194.79 & 141.63 \\
\hline Phase 4 & 9 & $130,781.6$ & 1236.18 & 10 & 33.63 & 0.869 & 8 & 9188.19 & 246.55 \\
\hline Unlock & 20 & $130,965.1$ & 1948.25 & 23 & 38.40 & 1.41 & 22 & $10,116.45$ & 191.04 \\
\hline First Wave & 186 & $136,100.8$ & 7237.63 & 180 & 36.13 & 8.19 & 178 & $10,740.42$ & 1247.73 \\
\hline Second Wave & 46 & $128,006.1$ & 3616.02 & 49 & 60.70 & 2.92 & 47 & $14,879.08$ & 246.43 \\
\hline
\end{tabular}


The results of the descriptive analysis clearly show that in the case of oil and stock exchange return, there is a considerable fall in the closing prices of indices and oil throughout the different phases of lockdown. However, the fall is quite steep during the initial stages of lockdown. In the case of oil price, the mean was 49 before lockdown, and after phase one, the mean average was 23 , whereas in the case of the stock exchange, the mean average was $11,560.40$ before lockdown, and it reached 8453.3 after the first phase of lockdown. This fall in oil prices is because of the lower demand for oil due to stagnation in transport and travel. However, the fall in stock price movement is because of the uncertain future and fear in the mind of investors and promoters. During all the phases of the lockdown, the mean and the prices of gold are showing a rising trend. The reason for such rise may be due to the perception of investors that consider gold to be the safest form of investment in times of such pandemics and crisis [33]. Figure 1 shows the price variation of all three commodities. Further, the descriptive statistics also show that during the first wave, the volatility is high in all three commodities in India. During the first wave, the National Stock Exchange of India and oil prices have a negative relationship; however, in the second wave, this relationship is positive. The plausible reason is that the level of uncertainty in the second wave is lower than in the first wave. In the second wave, the government of India has still not implemented complete lockdown, and even the state governments have implemented lockdowns only on the selected hotspots. The labor migration is also less in the second wave compared to the first one. Further COVID-19 vaccination drive is also going on at a national scale to overcome the spread of infection. To reduce the economic impact of the first wave, the Indian government has also provided financial stimulus to various industries. These positive approaches have created a sense of stability in the mind of investors. As a result, investors are more rational in making their investment choices during the second wave. Due to no partial lockdown during the second wave, global oil demand is rising, pushing oil prices even higher. Moreover, based on the positive approach of investors and the government, stock prices are also rising, and this is negatively affecting investment in the gold markets. Thus, gold prices are showing a falling trend.

Before proceeding with the post hoc test, we have checked the homogeneity of variance using the Levene test. The Levene test indicates that the data is not homogeneous in all three cases: gold, oil, and stock, with $p$-values less than $5 \%$, implying that we can proceed with the Games-Howell test, which is better suited for this type of data.

However, before employing the Games-Howell test, we used the Welch test to check if the difference in the mean of the stock and commodity markets during the various phases of lockdowns was important. The result of the Levene test of homogeneity of variance is notes in Table 3 attached below.

Table 3. Test of homogeneity of variance.

\begin{tabular}{ccccc}
\hline & Levene Statistic & df1 & df2 & Sig. \\
\hline Gold Prices & 6.239 & 5 & 122 & $0.000^{*}$ \\
Oil Prices & 6.372 & 5 & 127 & $0.000^{*}$ \\
Stock Indices & 8.295 & 5 & 117 & $0.000^{*}$ \\
\hline
\end{tabular}

Note: ${ }^{*}$ denotes 5 percent level of significance.

The result of the Welch test which is reported in Table 4 clearly shows that there is a significant difference among the means of all the three variables during the different phases of lockdown as the $p$-value is less than five percent level of significance but to see how the mean difference in each phase separately, we proceed with the results of Games-Howell test which is presented in Table 5. 
Table 4. Welch robust test of equality of means.

\begin{tabular}{ccccc}
\hline & Statistic $^{\text {a }}$ & df1 & df2 & Sig. \\
\hline Gold Prices & 165.371 & 5 & 39.464 & $0.000^{*}$ \\
Oil Prices & 160.149 & 5 & 39.825 & $0.000^{*}$ \\
Stock Indices & 106.048 & 5 & 33.765 & $0.000^{*}$ \\
\hline Note: * denotes 5 percent level of Significance ${ }^{\text {a }}$ asymptotically F distributed
\end{tabular}

Table 5. Games-Howell test for phase-wise comparison among the means.

\begin{tabular}{|c|c|c|c|c|c|}
\hline & (I) No Lockdown & (J) Lockdown & Mean Difference (I-J) & Std. Error & Sig. \\
\hline \multirow{5}{*}{ Gold } & No Lockdown & Phase 1 & $-10,128.9458 *$ & 1078.0053 & $0.000 *$ \\
\hline & & Phase 2 & $-16,157.4594 *$ & 720.1895 & 0.000 * \\
\hline & & Phase 3 & $-15,671.6608 *$ & 634.1572 & 0.000 * \\
\hline & & Phase 4 & $-16,991.6851 *$ & 664.9510 & 0.000 * \\
\hline & & Unlock & $-17,175.2117^{*}$ & 679.8152 & $0.000^{* *}$ \\
\hline \multirow{5}{*}{ Oil } & No Lockdown & Phase 1 & 26.76457 * & 1.43671 & $0.000 *$ \\
\hline & & Phase 2 & 37.85185 * & 4.43534 & 0.000 * \\
\hline & & Phase 3 & $24.31521 *$ & 1.61799 & $0.000^{* *}$ \\
\hline & & Phase 4 & 16.24939 * & 1.35200 & 0.000 * \\
\hline & & Unlock & 11.47861 * & 1.35633 & 0.000 * \\
\hline \multirow{5}{*}{ Stock } & No Lockdown & Phase 1 & 3107.01538 * & 187.69082 & $0.000 *$ \\
\hline & & Phase 2 & $2297.05000 *$ & 159.80683 & $0.000^{* *}$ \\
\hline & & Phase 3 & 2365.60909 * & 147.46471 & 0.000 * \\
\hline & & Phase 4 & 2372.20625 * & 165.89407 & 0.000 * \\
\hline & & Unlock & 1443.94545 * & 146.90541 & 0.000 * \\
\hline
\end{tabular}

Note: ${ }^{*}$ denotes 5 percent level of significance, ${ }^{* *} 1$ percent level of significance.

The results of the Games-Howell test show that in both the stock and commodity markets in terms of stock prices, gold, and oil prices, there is a significant difference among the mean comparison, before lockdown and during the different phases of lockdown. Table 5 shows that in the case of gold prices, the mean has a rising trend in all stages of lockdown, suggesting that gold prices have risen even during the spread of coronavirus. As a result, we can conclude that the pandemic has had a significant and positive impact on gold prices, and investors have shown a positive attitude toward gold investment. Oil prices and stock returns, on the other hand, have been declining in comparison to gold, implying that oil and stock have a strong negative correlation with the novel coronavirus. The results also show that during phase 1 and phase 2 of lockdown, the difference in means was higher due to a lack of sufficient information and prevalence of uncertainty. However, as the pandemic became less severe and people became more used to it, the mean value began to return to normal. Based on the findings, we can infer that the pandemic is having a significant impact on stock and oil prices in India. Coronavirus, on the other hand, has acted as an investment opportunity for gold prices.

We also used the heteroskedastic independent $t$-test to see how the stock and commodity markets behaved during the first and second waves of COVID-19 spread in India since the variance was not comparable. Table 6 shows the results of a heteroskedastic independent $t$-test, which indicates that the variance of the three variables was high during the first wave of COVID-19 spread in India, compared to the second wave. During the first wave, oil and stock returns had a detrimental association with coronavirus infections, but this relationship has flipped in the second wave. Similarly, gold prices rose during the first wave, but now are dropping from their previous levels in the second wave. 
Table 6. Results of the heteroskedastic independent $t$-test comparing the first and second waves of COVID-19 spread.

\begin{tabular}{ccccc}
\hline & Mean Difference & $\boldsymbol{t}$-Value & df & Sig. \\
\hline Stock values & -4143.65 & -40.97 & 211.46 & $0.000 *$ \\
Gold price & 8094.87 & 10.77 & 147.64 & $0.000^{*}$ \\
Oil price & -26.17 & -34.27 & 213.04 & $0.000 *$ \\
\hline
\end{tabular}

Note: * denotes 5 percent level of significance.

Thus, we can conclude from the above results that novel coronavirus has created a severe negative impact on the Indian stock and commodity markets during the first wave, compared to the second wave of COVID-19 spread. The next section of this paper focuses on how COVID-19 has affected the stock market of South Asian countries, namely Pakistan and Bangladesh, in comparison to the Indian stock market. We have employed a similar methodology on the data set of stock market returns of the selected South Asian countries during the pre- and post-lockdown pandemic periods and during the first and second waves of COVID-19 infection. Table 7 presents the descriptive analysis of the closing stock prices of all three countries during the pre- and post-lockdown period of COVID-19 pandemic.

Table 7. Descriptive analysis.

\begin{tabular}{cccccc}
\hline Stock Indices & COVID-19 & N & Mean & Std. Deviation & Std. Error Mean \\
\hline \multirow{2}{*}{ India } & Pre & 53 & $11,782.9821$ & 705.59 & 96.92 \\
& Post & 68 & 9332.2319 & 660.02 & 77.06 \\
Pakistan & Pre & 52 & $40,606.0087$ & 1960.84 & 271.92 \\
\multirow{2}{*}{ Bangladesh } & Post & 74 & $32,804.1342$ & 1940.12 & 220.22 \\
& Pre & 52 & 4421.8585 & 187.25 & 25.96 \\
\hline
\end{tabular}

The result of Table 7 shows that the mean value of stock performances for all three countries have shown a decreasing trend between the pre- and post-lockdown periods, depicting that stock performances of all three countries have been significantly affected by the COVID-19 pandemic. However, the performance of the Indian stock market is severely affected in comparison to the stock performance of Pakistan and Bangladesh. The plausible reason might be the severity of the infection in India as compared to Pakistan and Bangladesh. Lastly, we proceed with the Levene test to check homogeneity of variance and $t$-test to confirm whether the significant difference among the mean of stock market performance among the selected South Asian countries is due to the COVID-19 pandemic or not. Table 8 shows the results of the Levene test for equality of variances and $t$-test.

Table 8. Levene test for equality of variances and $t$-test.

\begin{tabular}{|c|c|c|c|c|c|c|c|}
\hline & $\mathbf{F}$ & $\mathbf{F}$ & Sig & $t$ & df & $\begin{array}{c}\text { Sig. } \\
\text { (2-Tailed) }\end{array}$ & $\begin{array}{c}\text { Mean } \\
\text { Difference }\end{array}$ \\
\hline \multirow{2}{*}{ India } & Equal variances assumed & 0.18 & 0.667 & 19.71 & 121 & $0.000 *$ & 2458.5 \\
\hline & Equal variances not assumed & & & 19.56 & 108.8 & $0.000 *$ & 2458.5 \\
\hline \multirow{2}{*}{ Pakistan } & Equal variances assumed & 0.13 & 0.717 & 22.13 & 125 & $0.000 *$ & 7794.8 \\
\hline & Equal variances not assumed & & & 22.10 & 109.2 & $0.000 *$ & 7794.8 \\
\hline \multirow{2}{*}{ Bangladesh } & Equal variances assumed & 25.2 & 0.000 & 14.17 & 87 & $0.000 * *$ & 459.9 \\
\hline & Equal variances not assumed & & & 16.08 & 70.4 & $0.000 * *$ & 459.9 \\
\hline
\end{tabular}

Note: * denotes 5 percent level of significance, ${ }^{* *} 1$ percent level of significance.

The results of the Levene test show that in the case of India and Pakistan, the variance is homogenous, as the $p$-value is more than a five percent level of significance, which means we can proceed with the $t$-test. As the $t$-test significance value is less than five percent, we can substantiate that the changes in the mean value of stock market performance during 
pre and post period of the analysis are due to the impact of coronavirus infection and increased market uncertainty. In the case of Bangladesh, however, the result shows that the variance is not homogeneous since the $p$-value is less than $5 \%$, offering less evidence about whether or not the reason for the variation is due to the COVID-19 pandemic. The stock market in Bangladesh was closed for two months due to the spread of COVID-19, which caused such a change in its results. Other macroeconomic disruptions, such as insufficient monetary expansion, confidence crises, the establishment of a floor price, and failure to control the contagion, as indicated by Haque and Chowdhury [34], have also led to such variations. Furthermore, we have also investigated the volatility of the stock market performances of the selected South Asian countries during the first and second waves of COVID-19 spread. Table 9 shows the heteroskedastic t-test results of the first and second waves. Based on the mean value, the results show that stock market volatility was higher in the first wave in both countries than in the second wave. During the first wave of COVID-19 infection, the stock markets in all three countries performed poorly but recovered in the second wave.

Table 9. Results of heteroskedastic independent $t$-test comparing the first and second waves of COVID-19 spread and stock market performance of South Asian countries.

\begin{tabular}{ccccccccc}
\hline & & N & Mean & Std. Dev. & $\begin{array}{c}\text { Mean } \\
\text { Difference }\end{array}$ & $\boldsymbol{t}$-Value & df & Sig. \\
\hline \multirow{2}{*}{ Stock values Pakistan } & Wave 1 & 177 & $37,289.40$ & 4002.74 & -8150.15 & -25.06 & 219.55 & $0.000 *$ \\
& Wave 2 & 52 & $45,378.38$ & 968.19 & & & \\
\multirow{2}{*}{ Stock values Dhaka } & Wave 1 & 135 & 4558.57 & 432.07 & -864.94 & -20.88 & 175.02 & $0.000 *$ \\
& Wave 2 & 49 & 5420.26 & 130.34 & & \\
\hline
\end{tabular}

Note: * denotes 5 percent level of significance.

The findings of the above analysis also corroborate the results of the GMM method reported in Table 10. The below table highlights the impact of COVID-19 infection on the stock market performance during the first wave of COVID-19 spread. We have considered only the first wave because the financial uncertainty was comparatively less during the second wave. The GMM results based on the coefficient and $p$-value conclude that during the first wave of COVID-19 spread, COVID-19 had a significant and negative effect on the stock markets performances of selected South Asian countries. Initial projection by UK Intensive Care National Audit and Research Centre suggested that South Asian countries like India, Pakistan, and Bangladesh are at higher risk of COVID-19 catastrophe [35]. The South Asian countries were at higher risk due to the presence of a higher population, higher comorbidities, poor health infrastructure, and socio-economic vulnerabilities. The South Asian countries also witnessed 21 percent of all the reported COVID-19 cases. All these projections and rise in cases initially created fear and uncertainty in the mind of the investors, which resulted in poor stock market performances during the first wave of COVID-19 spread. However, in the latter half of the COVID-19 pandemic, actual results highlighted that the death rate in South Asian countries was less compared to other parts of the world due to high immunity and the presence of a young population in such countries. The lower death rates and timely arrangement to fight the pandemic instilled confidence in the investors, which resulted in the recovery of stock market performances in the second wave of COVID-19 spread.

Table 10. GMM result.

\begin{tabular}{cccc}
\hline Dependent Variable: Stock Returns & $\begin{array}{c}\boldsymbol{t} \text { Value } \\
\text { (Coefficient) }\end{array}$ & $\boldsymbol{p}$ Value & Sargan Value $^{\mathbf{1}}$ \\
\hline India (COVID Cases) & $-3.19(-0.13)$ & $0.0001^{*}$ & 0.12 \\
Pakistan (COVID Cases) & $-4.12(-0.05)$ & $0.0004^{*}$ & 0.23 \\
Bangladesh (COVID Cases) & $-3.09(-0.43)$ & $0.0010^{*}$ & 0.41 \\
\hline
\end{tabular}

Note: * denotes 5 percent level of significance, ${ }^{1}$ Null hypothesis is that the instruments used are not correlated with the residuals, ${ }^{2}$ The null hypothesis is that the errors in the first-difference regression exhibit no second-order serial correlation. 
Thus, based on the findings of selected South Asian countries, we concluded that the COVID-19 pandemic has had a significant and negative impact on the financial market, which is consistent with previous studies, such as Gormsen and Koijen [36].

\section{Conclusion and Policy Implications}

This research aims at how COVID-19 has affected Indian stock and commodity markets, as well as the stock markets of the most affected South Asian countries. This study has used a homogenous variance test, the Welch test, Games-Howell test, heteroskedastic independent $t$-test, and GMM test to achieve the above objectives. We can infer from the findings of the study that the spread of the coronavirus has a significant and negative impact on the Indian stock market. Corona-induced lockdowns have a significant effect on investors' investment capabilities, as well as generating a sense of fear and anxiety about the future. Layoffs, company closures, and production have harmed the profitability of most sectors of the economy, including travel and tourism, real estate, and aviation, among others. Low profitability and insufficient demand, combined with the uncertainty caused by the pandemic, resulted in herb sales, causing a sharp drop in the stock market during the early stages of lockdown and the first wave of COVID-19 infection. However, as people became more aware of the virus and began to adapt, the stock market became more stable with each passing day, despite the increase in cases. The government measures that reduce the impact of a pandemic such as COVID-19 had a positive effect on stock returns, and this is particularly evident in the case of a second wave [37]. The economic stimulus packages introduced during the second wave positively influenced stock markets. Indian stock market and KSE-100 responded positively during the second wave due to the impact of fiscal stimulus and positive investor sentiments [38,39]. Central banks all over the world also sought to mitigate the adverse effects of the COVID-19 pandemic on financial markets by introducing temporary financial measures. For instance, the literature supports the positive impact of central bank actions on the real economy because central banks increase loan provision to businesses by easing financial conditions [40]. Other financial measures taken by central banks in response to COVID-19 include a ban on dividend payments, a payment moratorium, and the relaxation of countercyclical capital buffers. All these cumulative actions during the second wave resulted in the recovery of the stock markets.

When we look at the commodity market analysis for oil and gold, we can see that the findings are conflicting, as the coronavirus has had a negative and significant effect on oil prices, whereas a positive effect on the gold prices. During the first wave, the results show that oil prices have shown a decreasing trend. The persistent lockdown has resulted in the fall of oil demand in comparison to the supply side. In April 2020, oil demand was low by 30 percent compared to the last year, reaching a level not seen since 1995 [41]. Due to the low global demand, producers faced another issue of storage. During the first wave, the stocks of oil reached an all-time high in June 2020, which further resulted in the oil prices' drop [42]. On the supply side during the first wave, the OPEC+ alliance also failed to cut production, which resulted in some producers including Russia and Saudi Arabia flooding the oil market [43]. However, in the second wave, the implementation of the agreement to curb production among OPEC+ countries, the ease of lockdown restrictions, and the increase in demand cumulatively lead to the recovery of oil prices globally [44]. Thus, the result also supports the theoretical background of demand theory. COVID-19 has a positive effect on gold prices, which is likely due to the fact that, while gold does not provide much economic value on its own, it is a useful tool in times of uncertainty and disruption. The liquidity value of gold is also higher in comparison to other debt or real estate instruments. Apart from that, gold and equity instruments move in opposite directions with the fall in the equity, gold prices rise, and vice versa. Studies show that after the collapse of Lehman Brothers in September 2008 in the US, which led to a worldwide economic crisis, gold prices jumped from around \$700 an ounce in October 2008 to \$1900 an ounce in September 2011. Thus, we conclude that gold is a safer instrument to invest in during times of uncertainty and pandemics. 
In the context of selected South Asian countries, it can be inferred that the economic sustainability will be at high risk in these countries. The data collected from the Luohan Academy shows that India, Pakistan, and Bangladesh are the top three South Asian countries in terms of COVID positive cases. These three countries have the highest chances of systematic risk due to the high population, lower health infrastructure facilities, and high fiscal deficit as projected by pandemic economic indicator, Luohan Academy. The data of the International Monetary Fund highlights that South Asian countries also have the lowest mean spending of gross domestic product toward social security (0.9) in comparison to other countries affected by a novel coronavirus. The consistent fall in export remittance, tourism, and foreign inflows has considerably affected the balance of payments situations of South Asian countries. The prolonged lockdown imposed due to novel coronavirus has substantially affected the micro and small-scale industries as well, which account for 30 percent of the GDP. Thus, the aftereffect of these uncertainties and economic slowdown is reflected from the findings of this study, which conclude that the stock market of South Asian countries is severely affected by the pandemic-related economic uncertainty. However, the study also reveals that globally, the after-effect of the first wave of COVID-19 infection on the stock and commodity market is more severe compared to the second wave. Countries around the world are well prepared and extended better medical facilities in the second wave of the pandemic.

In response to the recent COVID-19 pandemic, each country has implemented various control measures, such as complete lockdown, smart lockdown based on hotspot analysis, and/or strict movement restrictions on its people [45]. However, the general public's compliance with the guidance provided by the relevant authority is critical to the effectiveness of any plan to combat COVID-19 [46]. For instance, between the two waves, both general concern for the emergency and perceived risk of infection increased, however, people in the second wave reported being more worried about the pandemic's economic effects than the health risk [47]. In these unprecedented times, governments are striving to implement economic recovery strategies that are both inclusive and long-term. The goals of the policy packages that have been announced so far vary from country to country. Some countries have made health a priority in order to alleviate the pressure on their health systems while also coping with the negative effects on their economies.

To overcome the economic uncertainty and sluggish growth, the following measures are recommended: first, to make a balance between lockdown and reopening of the economy, concentrated efforts are required by both the South Asian central banks and governments. Adequate fiscal stimulus is to be provided by the governments to the central banks to help in increasing the money supply and reviving the sluggish demand. South Asian governments must also instill sufficient trust in borrowers and entrepreneurs by implementing schemes that concentrate on loan disbursements at a fair pace, as well as providing sufficient relief from loan repayment moratorium periods, as the Indian government has done. Appropriate refinancing schemes, liquidity supports, relaxed debt payment structuring, and regulatory forbearance are required to encourage small, mediumscale, retail, and informal industries, which are the backbone of South Asian countries, which depend on them for $60 \%$ of their GDP [48]. In addition to the above, South Asian countries must strive to acquire support from international multilateral banks for their overburdened and highly reliant healthcare systems. COVID-19 is first and foremost a humanitarian tragedy that has global ramifications. However, it has also been an economic and financial sustainability crisis. Sustainability is gaining traction in society, especially in the business and investment community, and it is believed that this is critical to optimizing long-term economic growth and resilience. Based on the results, the study concludes that the pandemic's short-term impact on stock and commodity markets is much greater than its long-term impact. Thus, investors need to be very careful while making any short-term decisions. These findings contribute to the research by providing empirical evidence of how COVID-19 has impacted the Indian stock and commodity market along with the stock markets of South Asian countries. 


\section{Limitation and Future Work}

This study covers the time when novel coronavirus was showing a rising trend, and there is no specific study that focuses on analyzing how the market performs when this pandemic subsidizes. This study has also ignored the impact of macroeconomic variables on stock market fundamentals, thus providing sufficient scope for further research.

Author Contributions: Conceptualization, F.A. and A.A.S.; methodology, A.A.S. and S.G.; formal analysis, S.G. and M.A.K.; investigation, F.A. and M.A.K.; data curation, M.d.1.N.L.-G.; writingoriginal draft preparation, J.P.R.-R. and A.A.S.; writing-review and editing, M.d.1.N.L.-G. and J.P.R.-R., Funding, F.A, M.d.l.N.L.-G. and J.P.R.-R. All authors have read and agreed to the published version of the manuscript.

Funding: This research received no external funding.

Institutional Review Board Statement: Not applicable.

Informed Consent Statement: Not applicable.

Data Availability Statement: Publicly available datasets were analyzed in this study. This data can be found here: https://www.ecdc.europa.eu/en/publications-data, https://www.moneycontrol.c $\mathrm{om} / \mathrm{markets}$ /global-indices/.

Conflicts of Interest: The authors declare no conflict of interest.

\section{Appendix A}

Table A1. ADF Unit Root Test Result.

\begin{tabular}{|c|c|c|c|c|}
\hline & \multicolumn{2}{|c|}{ Individual Intercept } & \multicolumn{2}{|c|}{ Individual Intercept and Trend } \\
\hline & Level & First Diff ( $p$-Value) & Level & First Diff ( $p$-Value) \\
\hline India & & & & \\
\hline Stock return & 0.0561 & $0.0001 *$ & 0.0031 & $0.0000 *$ \\
\hline $\begin{array}{c}\text { COVID Cases } \\
\text { Pakistan }\end{array}$ & 0.0619 & $0.0000 *$ & 0.0702 & $0.0000 *$ \\
\hline Stock return & 0.0041 & $0.0001 *$ & 0.0012 & $0.0000 *$ \\
\hline $\begin{array}{c}\text { COVID Cases } \\
\text { Bangladesh }\end{array}$ & 0.0412 & $0.0000 *$ & 0.0113 & $0.0000 *$ \\
\hline Stock return & 0.0011 & 0.0004 * & 0.0210 & $0.0000 *$ \\
\hline COVID Cases & 0.0600 & $0.0001 *$ & 0.0813 & $0.0000 *$ \\
\hline
\end{tabular}

* 5 percent level of significance.

\section{References}

1. Sharif, A.; Aloui, C.; Yarovaya, L. COVID-19 pandemic, oil prices, stock market, geopolitical risk and policy uncertainty nexus in the US economy: Fresh evidence from the wavelet-based approach. Int. Rev. Financ. Anal. 2020, 70, 101496. [CrossRef]

2. World Health Organisation. Public Health Emergency of International Concern Declared. Available online: https: //www.who.int/docs/default-source/coronaviruse/transcripts/ihr-emergency-committee-for-pneumonia-due-to-thenovel-coronavirus-2019-ncov-press-brief-ing-transcript-30012020.pdf?sfvrsn=c9463ac1_2 (accessed on 30 January 2020).

3. World Health Organisation. WHO Characterizes COVID-19 as a Pandemic. Available online: https://www.who.int/docs/defau 1t-source / coronaviruse / transcripts / who-audio-emergencies-coronavirus-press-conference-full-and-final-11mar2020.pdf?sfv rsn=cb432bb3_2 (accessed on 11 March 2020).

4. Nippani, S.; Washer, K.M. SARS: A non-event for affected countries' stock markets? Appl. Financ. Econ. 2004, 14, 1105-1110. [CrossRef]

5. Kollias, C.; Manou, E.; Papadamou, S.; Stagiannis, A. Stock markets and terrorist attacks: Comparative evidence from a large and a small capitalization market. Eur. J. Political Econ. 2011, 27, S64-S77. [CrossRef]

6. Wang, Y. Meigu Chixu Baodie de Binggen Zai Naer [What Is the Root Cause of the Continued Collapse of US Stocks]. Shanghai Zhengquan Bao [Shanghai Security News]. 2020. Available online: http://news.cnstock.com/news,bwkx-202003-4507256 (accessed on 11 March 2020).

7. Broadstock, D.C.; Zhang, D. Social-media and intraday stock returns: The pricing power of sentiment. Finance Res. Lett. 2019, 30, 116-123. [CrossRef] 
8. Dumontier, P.; Raffournier, B. Accounting and capital markets: A survey of the European evidence. Eur. Account. Rev. 2002, 11, 119-151. [CrossRef]

9. Saleem, H.; Shabbir, M.S.; Khan, M.B. The short-run and long-run dynamics among FDI, trade openness and economic growth: Using a bootstrap ARDL test for co-integration in selected South Asian countries. South Asian J. Bus. Stud. 2020, 9, $279-295$. [CrossRef]

10. Chen, M.-H.; Jang, S.; Kim, W.G. The impact of the SARS outbreak on Taiwanese hotel stock performance: An event-study approach. Int. J. Hosp. Manag. 2007, 26, 200-212. [CrossRef]

11. Burch, T.R.; Emery, D.R.; Fuerst, M.E. Who Moves Markets in a Sudden Marketwide Crisis? Evidence from 9/11. J. Financ. Quant. Anal. 2016, 51, 463-487. [CrossRef]

12. Mirza, N.; Naqvi, B.; Rahat, B.; Rizvi, S.K.A. Price reaction, volatility timing and funds' performance during COVID-19. Financ. Res. Lett. 2020, 36, 101657. [CrossRef] [PubMed]

13. Fassas, A.P.; Papadamou, S.; Koulis, A. Price discovery in bitcoin futures. Res. Int. Bus. Financ. 2020, 52, 101116. [CrossRef]

14. Da, Z.; Engelberg, J.; Gao, P. In Search of Attention. J. Financ. 2011, 66, 1461-1499. [CrossRef]

15. Liu, H.; Manzoor, A.; Wang, C.; Zhang, L.; Manzoor, Z. The COVID-19 Outbreak and Affected Countries Stock Markets Response. Int. J. Environ. Res. Public Health 2020, 17, 2800. [CrossRef] [PubMed]

16. Del Giudice, A.; Paltrinieri, A. The impact of the Arab Spring and the Ebola outbreak on African equity mutual fund investor decisions. Res. Int. Bus. Financ. 2017, 41, 600-612. [CrossRef]

17. Chiang, T.C.; Jeon, B.N.; Li, H. Dynamic correlation analysis of financial contagion: Evidence from Asian markets. J. Int. Money Financ. 2007, 26, 1206-1228. [CrossRef]

18. Hasan, N.A.; Choi, S.Y.; Eppinger, M.; Clark, P.W.; Chen, A.; Alam, M.; Haley, B.J.; Taviani, E.; Hine, E.; Su, Q.; et al. Genomic diversity of 2010 Haitian cholera outbreak strains. Proc. Natl. Acad. Sci. USA 2012, 109, E2010-E2017. [CrossRef]

19. Siu, A.; Wong, Y.C.R. Economic Impact of SARS: The Case of Hong Kong. Asian Econ. Pap. 2004, 3, 62-83. [CrossRef]

20. Delisle, J. SARS, Greater China, and the Pathologies of Globalization and Transition. Orbis 2003, 47, 587-604. [CrossRef]

21. Chen, H.; Qian, W.; Wen, Q. The Impact of the COVID-19 Pandemic on Consumption: Learning from High Frequency Transaction Data. 2020. Available online: https://bfi.uchicago.edu/wp-content/uploads/Qian_COVID-Consumption-200414.pdf (accessed on 23 February 2021).

22. Albulescu, C. Coronavirus and Oil Price Crash. 2020. Available online: https://hal.archives-ouvertes.fr/hal-02507184v2/document (accessed on 23 February 2021).

23. Fornaro, L.; Wolf, M. COVID-19 Coronavirus and Macroeconomic Policy: Some Analytical Notes; Working Papers 1168; CREI/UPF: Barcelona, Spain; University of Vienna: Vienna, Austria, 2020.

24. Wren-Lewis, S. The economic effects of a pandemic. In Economics in the Time of COVID-19; Baldwin, R., Weder di Mauro, B., Eds.; CEPR Press: Oxford, UK; London, UK, 2020; pp. 109-112.

25. Mao, J.C. Quantitative Analysis of Financial Decisions; Macmillan: New York, NY, USA, 1969.

26. World Health Organization. COVID-19 Weekly Epidemiological Update, 23 February 2021. Available online: https: / /www.who. int/publications/m/item/weekly-epidemiological-update---23-february-2021 (accessed on 23 February 2021).

27. Islam, A.; Sayeed, A.; Rahman, K.; Ferdous, J.; Shano, S.; Choudhury, S.D.; Hassan, M.M. Spatiotemporal patterns and trends of community transmission of the pandemic COVID-19 in South Asia: Bangladesh as a case study. Biosaf. Health 2021, 3, 39-49. [CrossRef] [PubMed]

28. Chen, A.H.; Siems, T.F. The effects of terrorism on global capital markets. Eur. J. Political Econ. 2004, 20, 349-366. [CrossRef]

29. Arellano, M.; Bond, S. Some Tests of Specification for Panel Data: Monte Carlo Evidence and an Application to Employment Equations. Rev. Econ. Stud. 1991, 58, 277. [CrossRef]

30. Arellano, M.; Bover, O. Another look at the instrumental variable estimation of error-components models. J. Econ. 1995, 68, $29-51$. [CrossRef]

31. Chaibi, H.; Ftiti, Z. Credit risk determinants: Evidence from a cross-country study. Res. Int. Bus. Financ. 2015, 33, 1-16. [CrossRef]

32. Syed, A.A.; Aidyngul, Y. Macro economical and bank-specific vulnerabilities of nonperforming loans: A comparative analy-sis of developed and developing countries. J. Public Aff. 2020, e2414. [CrossRef]

33. Shafiee, S.; Topal, E. An overview of global gold market and gold price forecasting. Resour. Policy 2010, 35, 178-189. [CrossRef]

34. Haque, S.; Chowdhury, T.A. Impact of COVID-19 in Bangladesh Stock Market. Asian Financ. Bank. Rev. 2020, 4, $22-23$.

35. Babu, G.R.; Khetrapal, S.; John, D.A.; Deepa, R.; Narayan, K.V. Pandemic preparedness and response to COVID-19 in South Asian countries. Int. J. Infect. Dis. 2021, 104, 169-174. [CrossRef]

36. Gormsen, N.J.; Koijen, R.S.J. Coronavirus: Impact on Stock Prices and Growth Expectations. Rev. Asset Pricing Stud. 2020, 10, 574-597. [CrossRef]

37. Narayan, P.K. Can stale oil price news predict stock returns? Energy Econ. 2019, 83, 430-444. [CrossRef]

38. Alam, M.N.; Alam, S.; Chavali, K. Stock Market Response during COVID-19 Lockdown Period in India: An Event Study. J. Asian Finance Econ. Bus. 2020, 7, 131-137. [CrossRef]

39. Waheed, R.; Sarwar, S.; Sarwar, S.; Khan, M.K. The impact of COVID-19 on Karachi stock exchange: Quantile-on-quantile approach using secondary and predicted data. J. Public Aff. 2020, 20, e2290. [CrossRef]

40. Gortsos, C.V. The response of the European central bank to the current pandemic crisis: Monetary policy and prudential banking supervision decisions. Eur. Co. Financ. Law Rev. 2020, 17, 231-256. 
41. IEA. IEA Oil Market Report-April 2020. Available online: https:/ /www.iea.org/reports/oil-market-report-april-2020 (accessed on 12 June 2020)

42. IEA. Oil Market Report-August 2020. Available online: https://www.iea.org/reports/oil-market-report-august-2020 (accessed on 12 September 2020).

43. Blas, J.; Pismennaya, E. Saudis Boost Oil Output, Defying Trump's Plea to End Price War. Available online: https:/ /www.bloomb erg.com/news/articles/2020-04-01/saudi-arabia-resists-trump-s-attempt-to-broker-an-oil-war-truce (accessed on 12 May 2020).

44. Brower, D. Why the Record Opeccut Is no Match for Coronavirus Hit to Demand. Available online: https://www.ft.com/content /2a91fd26-c337-427f-8b24-9f53bc321bb2 (accessed on 12 May 2020).

45. Azlan, A.A.; Hamzah, M.R.; Sern, T.J.; Ayub, S.H.; Mohamad, E. Public Knowledge, Attitudes, and Practices towards COVID-19: A cross-sectional study in Malaysia. PLoS ONE 2020, 15, e0233668. [CrossRef] [PubMed]

46. Roy, D.; Tripathy, S.; Kar, S.K.; Sharma, N.; Verma, S.K.; Kaushal, V. Study of knowledge, attitude, anxiety \& perceived mental healthcare need in the Indian population during COVID-19 pandemic. Asian J. Psychiatry 2020, 51, 102083.

47. Iqbal, M.A.; Younas, M.Z. Public knowledge, attitudes, and practices towards COVID-19 in Pakistan: A cross-sectional study. Child. Youth Serv. Rev. 2021, 120, 120-105784.

48. Syed, A.A. Symmetric and Asymmetric Influence of Macroeconomic Variables on Stock Prices Movement: Study of Indian Stock Market. In New Challenges for Future Sustainability and Wellbeing (Emerald Studies in Finance, Insurance, and Risk Management); Özen, E., Grima, S., Gonzi, R.D., Eds.; Emerald Publishing Limited: Bingley, UK, 2021; pp. 319-339. [CrossRef] 